\title{
In situ preparation of water-soluble ginsenoside Rh2-entrapped bovine serum albumin nanoparticles: in vitro cytocompatibility studies
}

This article was published in the following Dove Press journal:

International Journal of Nanomedicine

29 May 2017

Number of times this article has been viewed

\author{
Priyanka Singh ${ }^{1,2}$ \\ Yeon Ju Kim' \\ Hina Singh' \\ Sungeun Ahn' \\ Verónica Castro-Aceituno' \\ Deok Chun Yang ${ }^{1,2}$ \\ 'Department of Oriental Medicine \\ Biotechnology, Ginseng Bank, \\ ${ }^{2}$ Graduate School of Biotechnology, \\ College of Life Sciences, Kyung Hee \\ University, Yongin, Republic of Korea
}

Correspondence: Priyanka Singh; Yeon Ju Kim

Department of Oriental Medicine Biotechnology, Ginseng Bank, College of Life Sciences, Kyung Hee University, Yongin 446-70I, Republic of Korea

$\mathrm{Tel}+82312012100$

Fax +82312022688

Email prnksingh254@gmail.com;

yeonjukim@khu.ac.kr

\begin{abstract}
The present study investigates a simple and convenient one-step procedure for the preparation of bovine serum albumin (BSA)-Rh2 nanoparticles (NPs) at room temperature. In this work, ginsenoside Rh2 was entrapped within the BSA protein to form BSA-Rh2 NPs to enhance the aqueous solubility, stability, and therapeutic efficacy of Rh2. The physiochemical characterization by high-performance liquid chromatography, nuclear magnetic resonance, Fourier transform infrared spectroscopy, field emission transmission electron microscopy, dynamic light scattering, and thermogravimetric analysis confirmed that the prepared BSARh2 NPs were spherical, highly monodispersed, and stable in aqueous systems. In addition, the stability of NPs in terms of different time intervals, $\mathrm{pHs}$, and temperatures $\left(20^{\circ} \mathrm{C}-700^{\circ} \mathrm{C}\right)$ was analyzed. The results obtained with different $\mathrm{pHs}$ showed that the synthesized BSA-Rh2 NPs were stable in the physiological buffer ( $\mathrm{pH} 7.4)$ for up to 8 days, but degraded under acidic conditions ( $\mathrm{pH}$ 5.0) representing the $\mathrm{pH}$ inside tumor cells. Furthermore, comparative analysis of the water solubility of BSA-Rh2 NPs and standard Rh2 showed that the BSA nanocarrier enhanced the water solubility of Rh2. Moreover, in vitro cytotoxicity assays including cell viability assays and morphological analyses revealed that Rh2-entrapped BSA NPs, unlike the free Rh2, demonstrated better in vitro cell viability in HaCaT skin cell lines and that BSA enhanced the anticancer effect of Rh2 in A549 lung cell and HT29 colon cancer cell lines. Additionally, anti-inflammatory assay of BSA-Rh2 NPs and standard Rh2 performed using RAW264.7 cells revealed decreased lipopolysaccharide-induced nitric oxide production by BSA-Rh2 NPs. Collectively, the present study suggests that BSA can significantly enhance the therapeutic behavior of $\mathrm{Rh} 2$ by improving its solubility and stability in aqueous systems, and hence, BSA-Rh2 NPs may potentially be used as a ginsenoside delivery vehicle in cancer and inflammatory cell lines.
\end{abstract}

Keywords: bovine serum albumin, ginsenoside Rh2, solubility, stability, cancer, inflammation

\section{Introduction}

Nanotechnology and development of nanoparticle (NP) carriers for the delivery of poor water-soluble drugs is a considerable area of research and has gained increased attention. ${ }^{1}$ Many drug delivery systems have been developed by utilizing organic, inorganic, and metal-based nanocarriers; however, achieving efficient drug loading or entrapment in NP carriers, with improved stability and availability of drug in its active form, is itself a challenging task. ${ }^{2}$ Thus, there is a continuous need for developing promising drug delivery nanocarriers which can overcome these limitations. ${ }^{3}$ Among various nanocarriers, biomacromolecular proteins have arisen as potential drug delivery carriers by overcoming the confines of conventional drug delivery systems 
which include poor aqueous solubility, bioavailability, and therapeutic efficacy due to damage caused to the normal cells. ${ }^{4}$ Many reports support the use of protein-based drug delivery systems carrying various pharmacologically important but water-insoluble drugs such as methotrexate, paclitaxel, and oxaliplatin in the treatment of various severe diseases such as cancer and inflammation., ${ }^{2,5,6}$ Especially, albumin-based nanocarriers are emerging as multipurpose and potent carriers for drug delivery with an enhanced pharmacokinetic profile of drugs. ${ }^{7,8}$ Serum albumin of size $66 \mathrm{kDa}$ has the advantage of being the most abundant plasma protein in humans playing a major role in various biological processes such as balancing plasma $\mathrm{pH}$, maintaining colloidal osmotic pressure, delivering nutrients to cells, and solubilizing long-chain fatty acids. ${ }^{8}$ Bovine serum albumin (BSA) and human serum albumin (HSA) have been applied as nanocarriers for the delivery of many essential drugs in the treatment of various diseases such as cancer, hepatitis $C$, diabetes, and rheumatoid arthritis. ${ }^{5,7,9}$ Many of them are clinically approved and available in the market for the treatment of various diseases, for instance, Abraxane (paclitaxel-albumin NPs) approved by the US Food and Drug Administration for the treatment of advanced non-small-cell lung cancer and metastatic breast cancer. ${ }^{9}$ The high abundance of this plasma protein in the human body and its small size and stability in $\mathrm{pH}$ range from 4 to 9 , and temperature up to $60^{\circ} \mathrm{C}$, for approximately 10 hours, make it a suitable carrier for transporting numerous therapeutic drugs in various human cell lines. ${ }^{10}$ Additionally, these protein-based drug delivery nanocarriers have the intrinsic property of preferential uptake by tumor and inflamed tissues. Additionally, they show little or no toxicity and immunogenicity, and are not biodegradable. Prominently, these protein nanocarriers possess many surface charge groups which are found to be advantageous in the loading or entrapment of numerous drug molecules. ${ }^{11}$ Moreover, the unique ligand delivery property of albumin is found to be advantageous in enhancing the solubility of various hydrophobic drugs combined with serum albumin by loading, entrapment, or conjugation and helps in improving the pharmacokinetics of drug molecules in a biological environment. ${ }^{9}$ These unique properties of serum albumin make it an ideal choice for drug delivery applications and development of drug delivery carriers. ${ }^{12}$

Panax ginseng Meyer is a well-known and pharmacologically important medicinal plant which is widely available in the People's Republic of China, Republic of Korea, and Japan. ${ }^{13}$ The main active components of $P$. ginseng are ginsenosides, which have been shown to possess a variety of medically beneficial effects, including anti-inflammatory, antioxidant, antidiabetic, and anticancer effects. ${ }^{14,15}$ The ginsenosides are triterpene glycosides which are divided into two major groups as major and minor ginsenosides. Rh2 was first isolated from red ginseng ( $P$. ginseng modified product), well known as a pure active compound of $P$. ginseng, and classified as triterpenoid saponin belonging to protopanaxadiol group of ginsenosides. Rh2 has been found to have many medicinal properties such as inhibition of cancer cell proliferation, antiallergic activity by stabilization of cell membrane, and antiobesity and anti-inflammatory activity by the inhibition of production of nitric oxide (NO) and prostaglandin E2. ${ }^{13,16-18}$ Recently, researchers have found that $\mathrm{Rh} 2$ could inhibit the growth of many kinds of cancer cells, including prostate cancer, breast cancer, hepatoma, gastric cancer, and colon carcinoma cells. ${ }^{19-22}$ Although Rh2 has been found to possess many pharmacological efficacies, low aqueous solubility which further reduces the bioavailability and nontarget delivery of $\mathrm{Rh} 2$ is a major challenge, which can be overcome by enhancing its water solubility, and hence its therapeutic efficacy, and reducing its side effects. ${ }^{13}$ In this work, we attempted to load BSA with Rh2 to form BSA-Rh2 NPs, which were expected to increase the aqueous solubility of $\mathrm{Rh} 2$, and additionally, were applied as potential nanocarriers which can exert antitumor and anti-inflammatory activity by potent delivery of $\mathrm{Rh} 2$ with passive target specificity to tumor and inflammatory cells. BSA was chosen as a nanocarrier by assuming that it could protect the active agents of $\mathrm{Rh} 2$ from proteolytic digestion and provide long circulation in the bloodstream. In this work, we further characterized the synthesized BSA-Rh2 NPs, based on several physiochemical parameters, using high-performance liquid chromatography (HPLC), nuclear magnetic resonance ( ${ }^{1} \mathrm{H}$ NMR), Fourier transform infrared spectroscopy (FT-IR), field emission transmission electron microscopy (FE-TEM), particle size analysis, dynamic light scattering (DLS), and thermogravimetric analysis (TGA). In addition, the timedependent stability, $\mathrm{pH}$ stability, and temperature stability of NPs were analyzed. Furthermore, a comparative analysis of the water solubility of BSA-Rh2 NPs and standard Rh2 was undertaken which demonstrated impressive results for BSA-Rh2 NPs. Moreover, in vitro cytotoxicity of BSA-Rh2 NPs and standard Rh2 was compared in HaCaT skin cell lines, A549 lung cancer cell lines, and RAW264.7 (murine macrophage) cell lines to understand the enhancement of efficacy of Rh2 by loading it in a BSA nanocarrier.

\section{Experimental \\ Materials}

BSA (molecular weight $[\mathrm{Mw}]=66,000 \mathrm{Da}$ ) was purchased from Sigma-Aldrich Co. (St Louis, MO, USA). Rh2 was 
purchased from Ginseng Genetic Resource Bank (Kyung Hee University, Yongin, Republic of Korea). The different cell lines were purchased from the Korean Cell Line Bank (Seoul, Republic of Korea). All other chemicals and solvents used were of analytical grade.

\section{Preparation of BSA-Rh2 NPs}

BSA-Rh2 NPs were prepared via desolvation, which is the quintessential preparation method. ${ }^{23}$ Briefly, BSA was dissolved in water and sonicated for 5-10 minutes. Afterwards, the BSA-water mixture was kept under vigorous magnetic stirring at room temperature. Stirring was continued for 10 minutes, and then Rh2 dissolved in ethanol was added dropwise to the BSA-water solution such that the ethanoldissolved Rh2 was well dispersed in BSA-water mixture. The reaction mixture was continuously stirred at room temperature for the next 24 hours. The resulting mixture was transferred to a dialysis membrane (MWCO:3000) and dialyzed against an excess amount of methanol/distilled water $(75: 25, \mathrm{v} / \mathrm{v})$ for 1 day, and distilled water for 2 days. Finally, the dialyzed solution was lyophilized to obtain the BSA-Rh2 NPs in powder form for further characterization and in vitro applications.

\section{Characterization techniques}

The purity and loading of Rh2 in the BSA-Rh2 NPs were calculated by HPLC. The structure of BSA-Rh2 NPs was confirmed by ${ }^{1} \mathrm{H}$ NMR and FT-IR. ${ }^{1} \mathrm{H}$ NMR spectra were recorded at $300 \mathrm{MHz}$ (JEOL, Tokyo, Japan), for which the samples were dissolved in $\mathrm{D}_{2} \mathrm{O}$ or $\mathrm{CD}_{3} \mathrm{OD}$. FT-IR spectra of the NPs were recorded by an FT-IR spectrophotometer (PerkinElmer Inc., Waltham, MA, USA) over the range of $4,000-450 \mathrm{~cm}^{-1}$ using $\mathrm{KBr}$ pellets. The spectra recorded were plotted as transmittance $(\%)$ versus wavenumber $\left(\mathrm{cm}^{-1}\right)$. The morphology and shape of BSA-Rh2 NPs in a dried state were determined by FE-TEM using a JEM-2000F (JEOL) instrument operated at an acceleration voltage of $200 \mathrm{kV} .{ }^{24}$ To prepare a sample for FE-TEM, a drop of BSA-Rh2 NPs mixture was diluted with water and was put onto a holey carbon film supported on a 200-mesh copper grid, and further allowed to air-dry. ${ }^{25}$ FE-TEM was used to analyze the selected area (electron) diffraction (SAED) and fast Fourier transform (FFT) pattern of BSA-Rh2 NPs. ${ }^{26}$ The hydrodynamic particle size distribution, polydispersity index, and zeta potential were analyzed using a DLS instrument at $25^{\circ} \mathrm{C}$ (Photal or Otsuka Electronics, Hirakata, Japan). The BSA-Rh2 NPs sample was dispersed in water, as a reference, a dispersive medium of pure water with a refractive index of 1.3328 , viscosity of 0.8878 , and dielectric constant of 78.3 was used. ${ }^{27-29}$ TGA was performed on a TGA machine (SDT Q600; TA Instruments, New Castle, DE, USA). For TGA analysis, the product was placed in an alumina pan and heated from $20^{\circ} \mathrm{C}$ to $700^{\circ} \mathrm{C}$ at a ramping time of $10^{\circ} \mathrm{C} /$ minute.

For analyzing the time- and $\mathrm{pH}$-dependent stability of NPs, DLS was conducted to measure the NPs size at regular time intervals. For this, the BSA-Rh2 NPs were dispersed in either phosphate-buffered saline (PBS, $\mathrm{pH} 7.4$ ) or acetate buffer ( $\mathrm{pH}$ 5.0), and the NPs size was measured at regular time intervals. The solubility test was conducted by dissolving the same concentration of standard $\mathrm{Rh} 2$ and $\mathrm{Rh} 2$ entrapped in BSA-Rh2 NPs in water at 0 and 24 hours, followed by visual analysis, corresponding microscopic analysis $(\times 400$; Optinity; Korean Labtech, Namyangju, Republic of Korea), and HPLC analysis for measuring the dissolved $\mathrm{Rh} 2$ concentration. We made sure that the BSA-Rh2 NPs were taken at different concentrations such that the concentration of free $\mathrm{Rh} 2$ was comparable to that of the albumin-entrapped $\mathrm{Rh} 2$, thus making a thorough evaluation possible. ${ }^{30}$

\section{In vitro cell culture and cell cytotoxicity}

The human cell lines A549 and HT29 were purchased from the American Type Culture Collection (ATCC) (Manassas, VA, USA) and Korean Cell Line Bank (Seoul, Republic of Korea). RPMI 1640 culture medium (GenDEPOT Inc., Barker, TX, USA), supplemented with 10\% fetal bovine serum (FBS; Thermo Fisher Scientific, Waltham, MA, USA), was used to grow the cell lines at $37^{\circ} \mathrm{C}$ in a humidified incubator with a $5 \% \mathrm{CO}_{2}$ atmosphere. Cell viability was determined by MTT assay. For MTT assay, cells were seeded in 96-well plates at a density of $1 \times 10^{5}$ cells/mL. After 24 hours of incubation, the cells were treated with various concentrations of BSA-Rh2 NPs and standard ginsenoside Rh2 for 24 hours. After incubation, $10 \mu \mathrm{L}$ of the MTT stock solution $(5 \mathrm{mg} / \mathrm{mL})$ was added to each well and incubated for 4 hours. Then, the supernatants were removed and replaced with $100 \mu \mathrm{L}$ of dimethyl sulfoxide (DMSO). The amount of formazan formed by viable cells was measured using multi-model plate reader (BioTek Instruments, Winooski, VT, USA) at a test wavelength of $570 \mathrm{~nm}$ with a reference wavelength of $630 \mathrm{~nm}$. In addition, cytotoxicity assay was conducted in HaCaT skin cell lines to analyze the cell viability. ${ }^{31}$

\section{Hoechst nuclear staining}

Hoechst 33258 staining was performed to study the apoptotic induction in A549 and HT29 cells by BSA-Rh2 NPs. For this, cells were seeded into a six-well plate at a density of $1 \times 10^{5}$ cells/well in $2 \mathrm{~mL}$ medium and incubated at $37^{\circ} \mathrm{C}$ with $5 \% \mathrm{CO}_{2}$ overnight. The cells were then treated with $15 \mu \mathrm{M}$ of 
Rh2, standard Rh2, and BSA-Rh2 NPs. After treatment, the cells were stained with Hoechst 33258 solution at $2 \mu \mathrm{g} / \mathrm{mL}$ for 20 minutes following our previous protocol. ${ }^{31}$ Scale bar $(10 \mu \mathrm{m})$ was added using ImageJ software.

\section{Anti-inflammatory activity of BSA-Rh2 NPs}

Murine macrophage cell lines (RAW 264.7) were seeded at a density of $5 \times 10^{3}$ cells/well in a 96-well microplate in RPMI1640 medium containing 10\% (v/v) FBS and 1\% (v/v) penicillin/streptomycin, and incubated at $37^{\circ} \mathrm{C}$ in a humidified atmosphere containing $5 \% \mathrm{CO}_{2}$ and $95 \%$ air for 24 hours. To determine the influence of BSA-Rh2 NPs and standard Rh2 on cell viability, the cells were treated with various concentrations of the sample for 24 hours. After 1-day treatment, cell viability was evaluated by MTT assay. Ten microliters of MTT solution $(5 \mathrm{mg} / \mathrm{mL})$ was added to each well, and the plates were incubated for an additional 3-4 hours, and the formazan formed was dissolved in DMSO. Then, the absorbance of each well was recorded on a Synergy 2 multi-mode microplate reader at $570 \mathrm{~nm}$ (BioTek Instruments). The optical density of formazan formed in control (untreated) cells was taken as $100 \%$. To measure the nitrite level, RAW 264.7 cells were pretreated with BSA-Rh2 NPs and standard Rh2 for 1 hour and then stimulated with $1 \mu \mathrm{g} / \mu \mathrm{L}$ lipopolysaccharide (LPS) in the presence of the samples. The cells were incubated for 24 hours, after which Griess reagent was used to determine the nitrite levels in the medium. Briefly, $100 \mu \mathrm{L}$ of supernatant was mixed with an equal volume of the Griess reagent. The resultant absorbance at $540 \mathrm{~nm}$ was measured using a microplate reader (BioTek Instruments). A standard sodium nitrite curve was included for each experiment. ${ }^{32}$

\section{Statistical analysis}

The statistical significance of differences between control versus standard Rh2 and BSA-Rh2 NPs groups was determined using a Student's $t$-test. $P<0.05$ was considered to be significant, and is indicated in figures with asterisks. ${ }^{33}$

\section{Results and discussion Preparation and physicochemical characterization of BSA-Rh2 NPs}

BSA drug delivery system has recently gained attention and been applied for the delivery of numerous therapeutic drugs in different prospects, for instance, nanocarrier development, drug delivery, sensing, self-assembly, imaging, etc. ${ }^{10,34}$ Albumin-based nanocarriers are designated as drug delivery carrier materials as albumin is the most abundant blood protein, nontoxic and biocompatible in nature, and has abundant surface functional groups, all of which are quite helpful for drug loading or entrapment and binding of various biological molecules. ${ }^{12}$ Importantly, serum proteins naturally found in the blood are chiefly responsible for the maintenance of blood $\mathrm{pH}$, and are nontoxic, biodegradable, and nonimmunogenic in nature. ${ }^{35,36}$ The current study shows that BSA can be used as a nanocarrier for the delivery of Rh2, owing to its easy availability and biocompatibility. Various albumin-based NPs for drug delivery have been synthesized by desolvation method, among which BSA confers the drug with a great dispersibility and biocompatibility, in addition to providing a multifunctional surface for conjugation with other targeting molecules. ${ }^{23}$ In this study, BSA-Rh2 NPs were prepared by desolvation method, using ethanol as a desolvating agent. Figure 1 unveils the schematic illustration of the preparation BSA-Rh2 NPs, their characterization, and action mechanism involved in enhancing the aqueous solubility and anticancer and anti-inflammatory effects of Rh2. The desolvation method allows the preparation of BSA-Rh2 NPs with a homogeneous distribution, which remain stable in water and cell culture medium.

\section{HPLC and 'H NMR analysis of BSA-Rh2 NPs}

The amount of Rh2 loaded in the BSA-Rh2 NPs was determined by quantification of Rh2 residue in BSA-Rh2 NPs using HPLC. As shown in Figure 2 BSA-Rh2 NPs showed a clear peak of $\mathrm{Rh} 2$, and the amount of loading was $0.36 \mathrm{mg}$ of $\mathrm{Rh} 2 / \mathrm{mg}$ of BSA-Rh2 NPs. The ${ }^{1} \mathrm{H}$ NMR results of BSARh2 NPs exhibited the characteristic peak of Rh2 (Figure 3). A similar peak in ${ }^{1} \mathrm{H}$ NMR results has been reported as a result of conjugation of ginsenoside $\mathrm{CK}$ with glycol chitosan for enhancing the solubility and stability of CK. ${ }^{30}$

\section{FT-IR analysis of BSA-Rh2 NPs}

Several interactions play an important role in the binding of protein with small drug molecules, for instance, hydrophobic force, electrostatic interactions, van der Waals interactions, and hydrogen bonds. The FT-IR results of BSA-Rh2 NPs also exhibited the characteristic peak of Rh2 (Figure 4). The FT-IR results demonstrated that a major shift in peaks may be attributed to the cross linking among the positively charged amino groups of proteins and interaction of $\mathrm{Rh} 2$ with the residual amide species. Rh2 moved into the hydrophobic microenvironment of serum proteins and interacted with the hydrophobic pockets of the proteins. This concept could be 


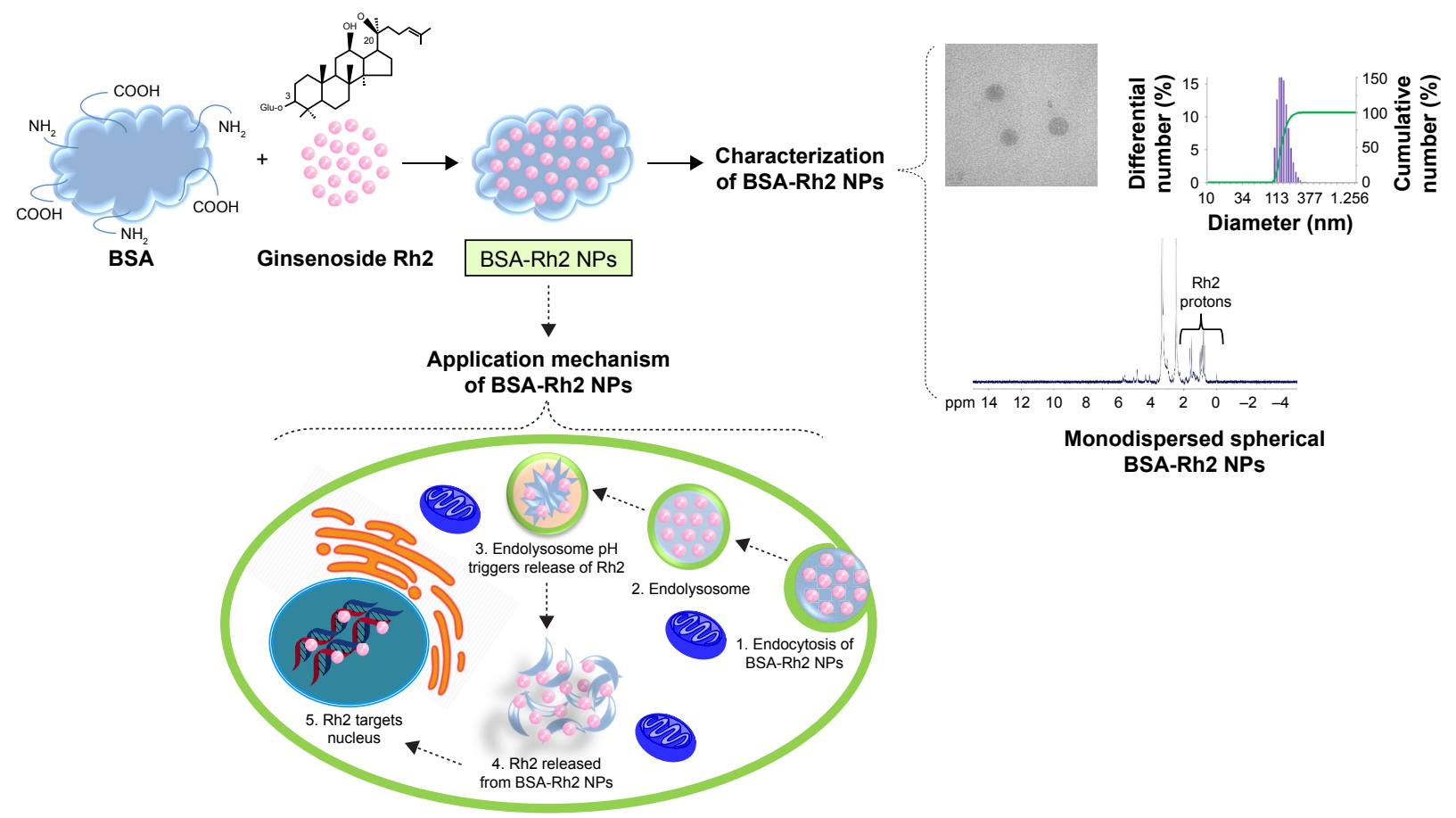

Figure I Schematic illustration of the BSA-Rh2 NPs synthesis and application mechanism for anticancer and anti-inflammatory efficacy. Abbreviations: BSA, bovine serum albumin; NPs, nanoparticles.

demonstrated by loading Rh2 in HSA as well, to apply HSA in future for drug delivery applications in the human body. ${ }^{7}$ Interaction of Rh2 with serum proteins mainly involves hydrophobic force, hydrogen bonding, and van der Waals interaction. ${ }^{35}$ As reported for numerous other drug molecules, Rh2 may interact with the tryptophan residues (Trp 212)
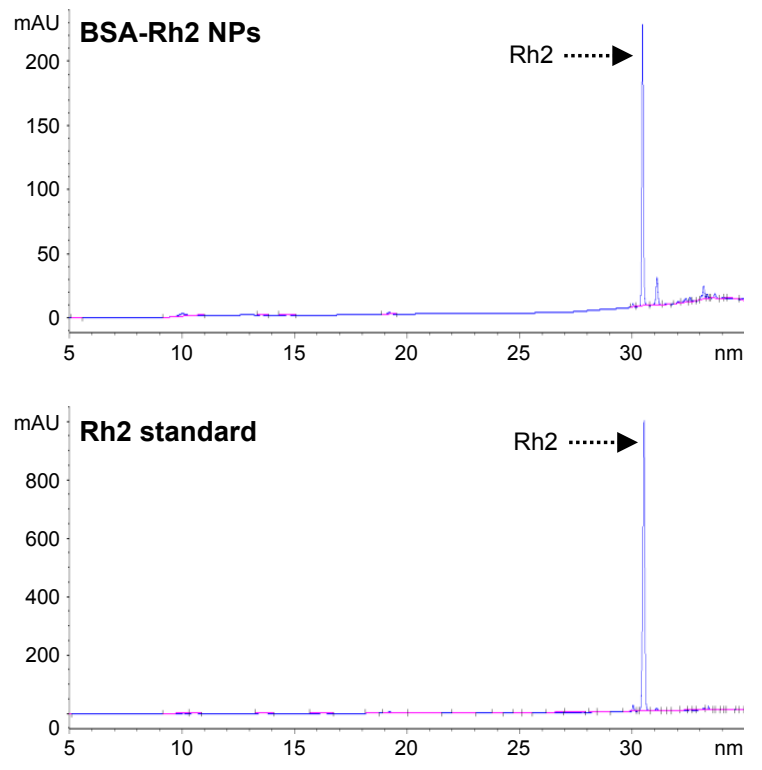

Figure 2 HPLC analysis of BSA-Rh2 NPs as compared with standard Rh2. Abbreviations: BSA, bovine serum albumin; NPs, nanoparticles; HPLC, highperformance liquid chromatography. located inside the hydrophobic BSA pocket. ${ }^{8}$ Thus, the HPLC, ${ }^{1} \mathrm{H}$ NMR, and FT-IR analysis of BSA-Rh2 NPs revealed sufficient entrapment of Rh2 in BSA-Rh2 NPs.

\section{Size and morphology of BSA-Rh2 NPs}

The size of the nanocarrier system plays a crucial role in drug delivery, as the NPs up to $400 \mathrm{~nm}$ are preferentially accrued in the tumor microenvironment via "enhanced permeability and retention (EPR)" effect. ${ }^{30}$ Figure 5 shows the spherical shape and surface morphology of the BSA-Rh2 NPs with $30-50 \mathrm{~nm}$ size as determined by the FE-TEM. ${ }^{36,37}$ The images of the Rh2-loaded albumin NPs showed a spherical morphology. This supported that incorporation in BSA proteins leads to the formation of spherical NPs and their size falls within the optimal size range for NPs for drug delivery applications. SEAD and FFT pattern of BSA-Rh2 NPs was evaluated using FE-TEM.

The size distribution of the BSA-Rh2 NPs was studied using DLS. The average hydrodynamic size of BSA-Rh2 NPs was found to be $175.8 \mathrm{~nm}$ (Figure 6A). According to the previous reports, less than $200 \mathrm{~nm}$ NPs prefer to accumulate in tumor tissues due to the EPR effect and can remain in blood circulation for a long time due to avoidance of the recognition by the reticuloendothelial system. ${ }^{30}$ The hydrodynamic diameter was relatively higher than the diameters indicated by the FE-TEM results, which could be due to the presence 

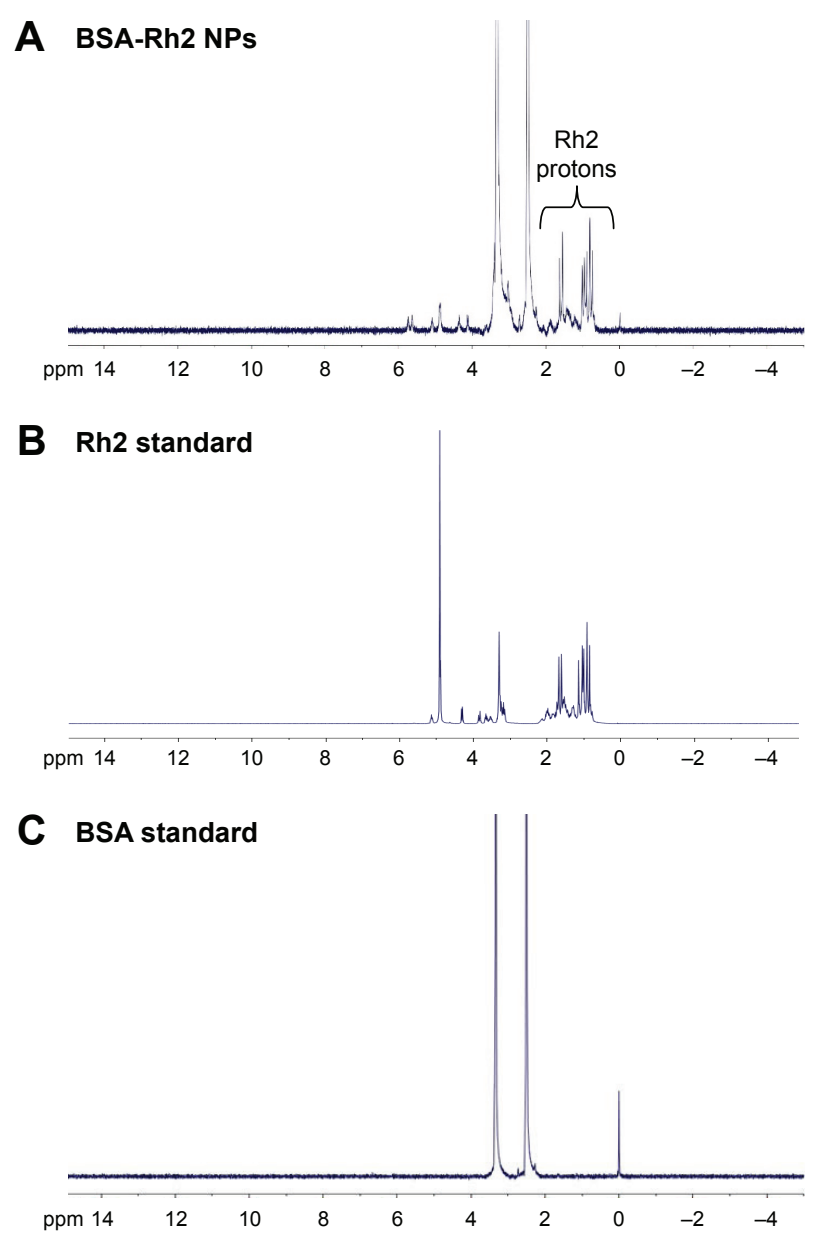

Figure 3 'H NMR analysis of BSA-Rh2 NPs (A), standard Rh2 (B) and standard BSA (C).

Abbreviations: BSA, bovine serum albumin; NPs, nanoparticles.

of water surrounding the BSA-Rh2 NPs as evaluated by DLS in comparison with the sizes measured in the dried state by FE-TEM.

\section{Zeta potential analysis of BSA-Rh2 NPs}

The stability of the NPs could be ascribed to the considerably higher zeta potential. The zeta potential value of the BSA-Rh2 NPs was found to be $-80.2 \mathrm{mV}$ (Figure 6B) as compared to previously reported drug-encapsulated BSA NPs; for instance, niclosamide-BSA NPs had a zeta potential value of $-34.2 \mathrm{mV}$, while pristine BSA had $-17.9 \mathrm{mV}$. Zhao et al showed the zeta potential value of paclitaxel-loaded BSA NPs to be $-30 \mathrm{mV} .{ }^{6}$ Thus, the BSA-Rh2 NPs generated in the current study are highly stable, which lies in line with the previous reports. The zeta potential value positions within the stable range, signifying that the BSA-Rh2 NPs are stable. Moreover, the electrostatic repulsive force due to the

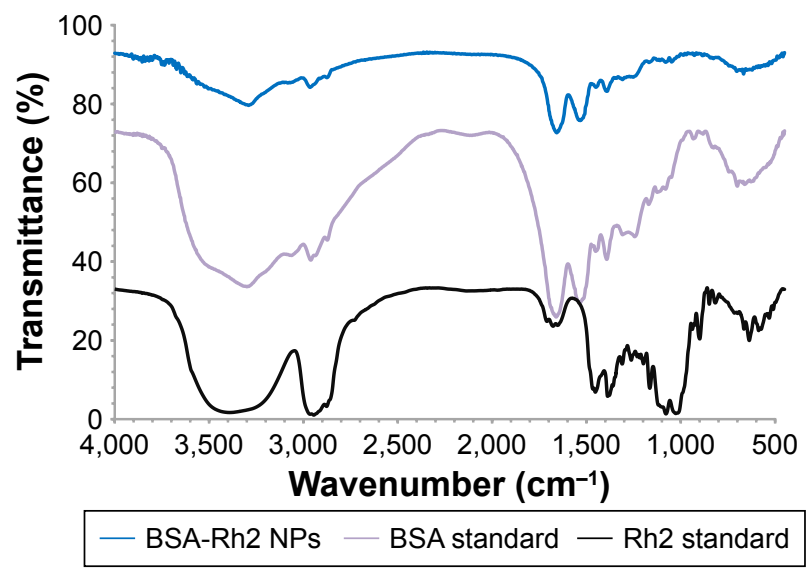

Figure 4 FT-IR pattern of BSA-Rh2 NPs corresponding to standard BSA. Abbreviations: BSA, bovine serum albumin; NPs, nanoparticles.

negative surface charge among the BSA-Rh2 NPs affords high stability to the colloidal solution by preventing the NPs from agglomerating in the colloidal state. ${ }^{6}$

\section{Thermal stability of BSA-Rh2 NPs}

To analyze the loading, TGA of standard Rh2, pure BSA as control, and BSA-Rh2 NPs was conducted, which depicted slower degradation rate of protein-drug nanoformulation indicating its improved stability as compared to standard $\mathrm{Rh} 2$. The TGA profile showed the temperature stability and the degradation of BSA-Rh2 NPs with respect to increasing temperature (Figure 6C). From the results, it was clear that the particles started to degrade from $250^{\circ} \mathrm{C}$, and beyond $300^{\circ} \mathrm{C}$, an abrupt decrease in weight loss was found which could be due to the result of loss of small molecules such as carbon dioxide and ammonia. The standard Rh2 showed complete and sudden degradation at $400^{\circ} \mathrm{C}$, whereas BSA$\mathrm{Rh} 2 \mathrm{NPs}$ showed a slow and steady degradation profile from temperatures ranging from $350^{\circ} \mathrm{C}$ to $500^{\circ} \mathrm{C}$. At $300^{\circ} \mathrm{C}$, there was a considerable difference in weight loss; $10.50,4.32$, and $7.50 \mathrm{wt} \%$ weight loss was observed for BSA-Rh2 NPs, standard Rh2, and control BSA, respectively. Beyond $600^{\circ} \mathrm{C}$, a faster rate of degradation for BSA-Rh2 NPs was observed as compared to BSA, which may be due to the crystalline nature of Rh2 molecules entrapped in BSA-Rh2 NPs. Although no significant change was observed in BSA, due to the char formation in nitrogen atmosphere, an additional step was required related to the combustion of the char product in air atmosphere. A similar TGA profile of niclosamide-entrapped albumin NPs has been reported. ${ }^{23}$ Thus, the results clearly showed that the loading of Rh2 in BSA nanocarrier enhances its stability as compared with standard Rh2. Additionally, 

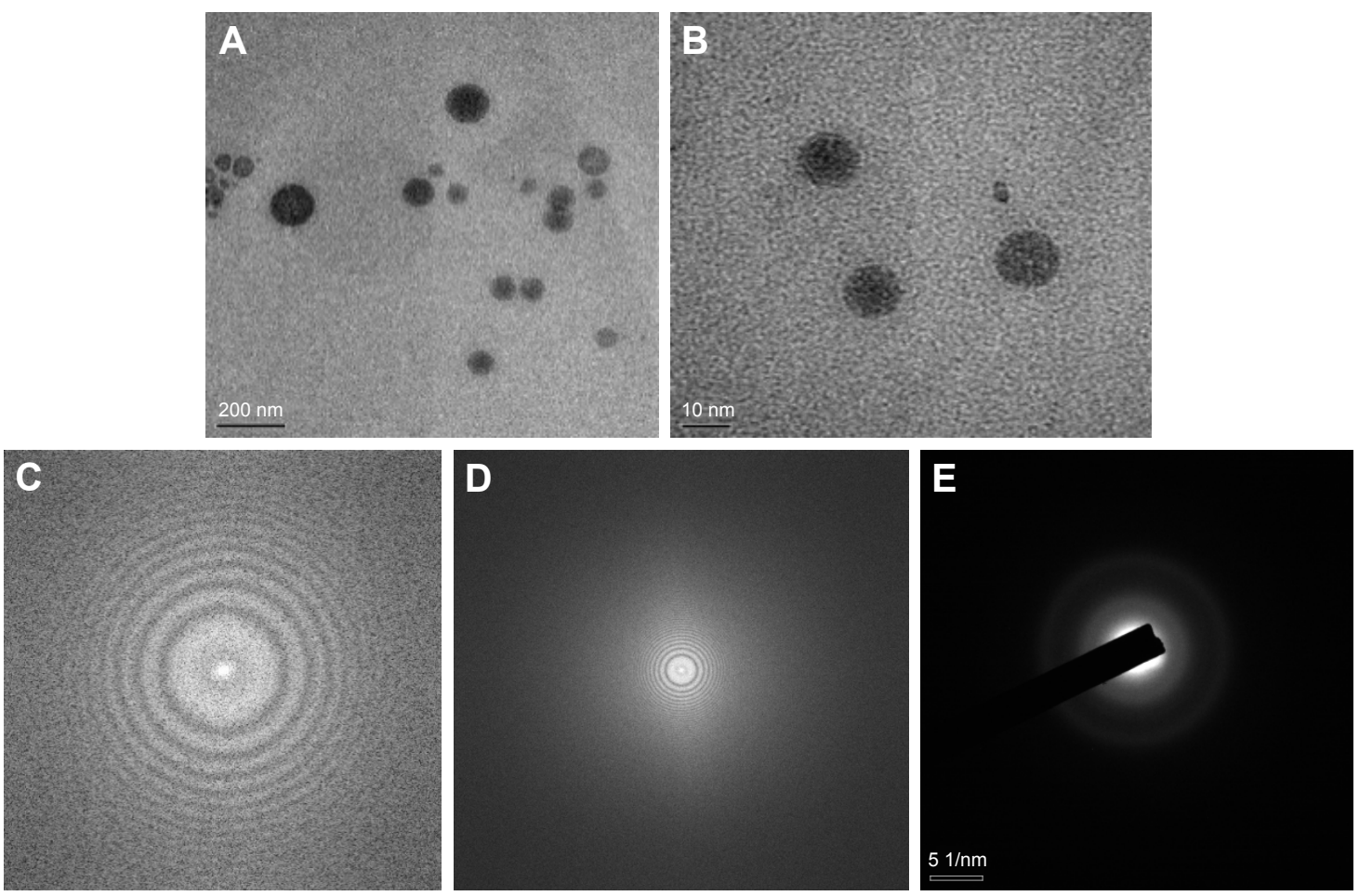

Figure 5 FE-TEM shape, morphology, SEAD and FFT characterization of BSA-Rh2 NPs.

Notes: Particles size at $200 \mathrm{~nm}(\mathbf{A})$, at $10 \mathrm{~nm}$ (B), FFT of NPs (C and D), SEAD pattern of NPs (E).

Abbreviations: FE-TEM, field-emission transmission electron microscope; SEAD, selected area (electron) diffraction; FFT, fast fourier transform; BSA, bovine serum albumin; NPs, nanoparticles.

\section{A}

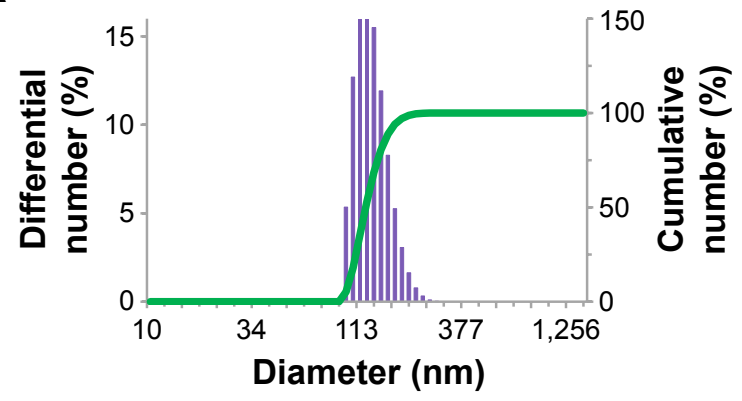

B

Frequency $(\mathrm{Hz})$

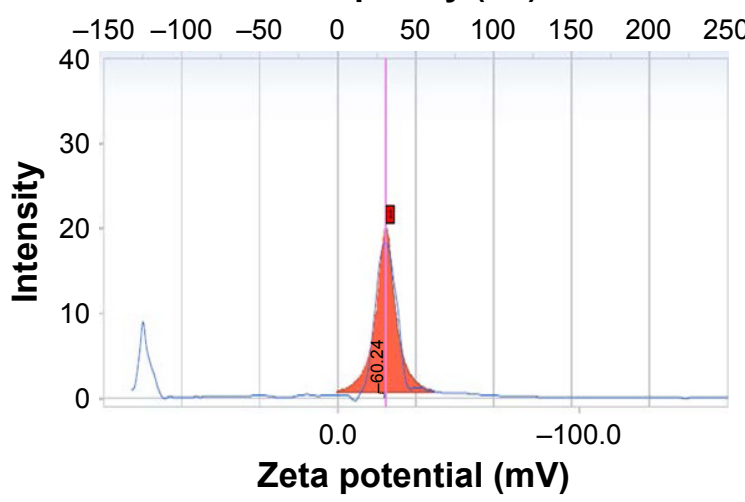

C

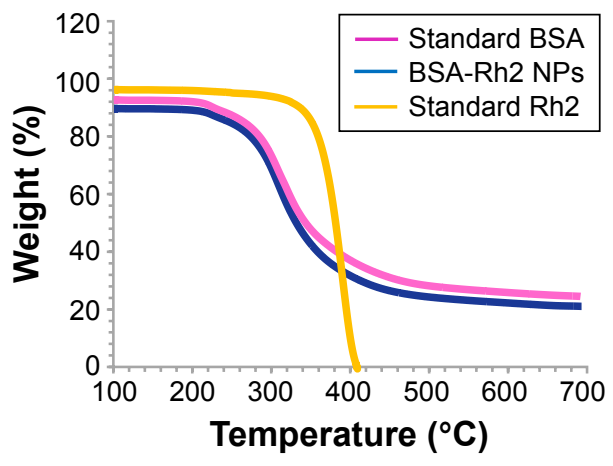

Figure 6 Characterizations of BSA-Rh2 NPs by particle size analysis (A), zeta potential analyzer (B), and TGA analysis (C), respectively. Abbreviations: BSA, bovine serum albumin; NPs, nanoparticles. 

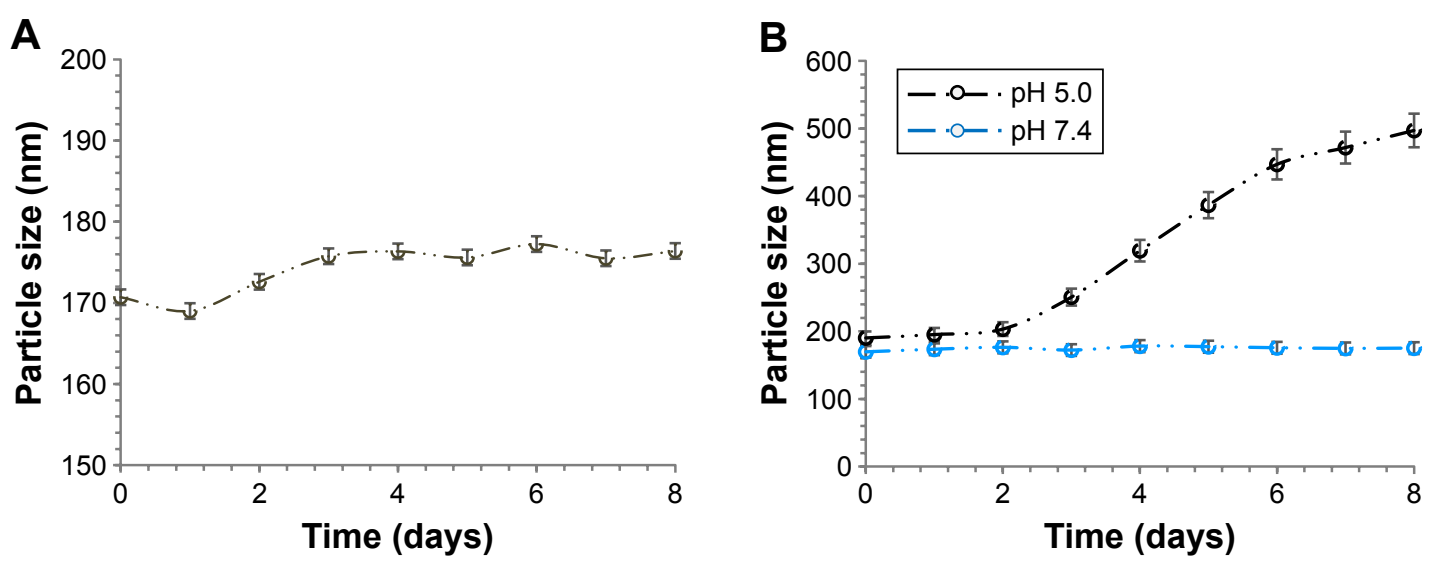

Figure 7 Time dependent stability of BSA-Rh2 NPs using particles size analysis, with respect to different time interval (A) and pH conditions (B). Abbreviations: BSA, bovine serum albumin; NPs, nanoparticles.

the temperature stability profile showed that the products are successfully degraded at higher temperature.

\section{Time-dependent and $\mathrm{pH}$-dependent stability of BSA-Rh2 NPs}

Several important factors including molecular weight, size of NPs, blood circulation time, and stability contribute to the delivery and accumulation of NPs in specific cells. Thus, the stability of the prepared BSA-Rh2 NPs was investigated at different time intervals for 8 days, to analyze the increase in size of BSA-Rh2 NPs due to NPs degradation. As shown in Figure 7A, up to 8 days, there was no drastic change in the size of BSA-Rh2 NPs, which suggests the stability of BSA-Rh2 NPs at room temperature in an aqueous system. The BSA-Rh2 NPs remained stable for 8 days, representing their thermodynamic stability in aqueous environment. Further, in analysis of pH-dependent stability, the NPs degradation was observed by measuring the particle size at $37^{\circ} \mathrm{C}$ in PBS (pH 7.4) as a function of time (Figure 7B). ${ }^{10}$ Conversely, NP size was increased at $\mathrm{pH} 5.0$ in acidic conditions, primarily due to the hydrolysis of Rh2 from BSA-Rh2 NPs, resulting in the formation of large aggregates of the hydrolyzed $\mathrm{Rh} 2$ through hydrophobic interaction. The most noteworthy finding from our stability analyses was the high stability of BSA-Rh2 NPs in physiological buffer, which indicated that the NPs may exhibit prolonged circulation in vivo. ${ }^{23,30}$ From these observations, it was clear that the prepared BSA-Rh2 NPs are stable during blood circulation, whereas the BSARh2 NPs prompt Rh2 release after reaching the tumor site due to acidic $\mathrm{pH}$ condition in tumor cells. Thus, BSA-Rh2 NPs are advantageous compared to the standard $\mathrm{Rh} 2$ for effective cancer therapy. Additionally, the high molecular weight of BSA helps in prolonged circulation of BSA-Rh2 NPs in the blood which further enhances tumor targeting by the EPR effect and by minimizing macrophage uptake. ${ }^{30}$

\section{Solubility of BSA-Rh2 NPs}

Aqueous solubility is one of the most important physicochemical factors for drug absorption. Furthermore, good aqueous solubility has been reported to play a role in enhancing other pharmacokinetic properties including bioavailability, membrane flux, and therapeutic activity. To enhance the solubility of Rh2, it was entrapped in BSA which led to the formation of BSA-Rh2 NPs. BSA considerably enhances the solubility, bioavailability, and antitumor activity of various anticancer drugs. Due to the hydrophilic nature of BSA, the prepared BSA-Rh2 NPs were readily soluble in PBS ( $\mathrm{pH}$ 7.4) or water, whereas free $\mathrm{Rh} 2$ was insoluble even at the same and much lower concentrations, as well (Figure 8). The synthesized BSA-Rh2 NPs exhibited good solubility and stability in an aqueous system for up to a month by avoiding precipitation, thus suggesting that the water dispersion ability is significantly improved due to the coating with BSA. Similarly, Ji et al, reported that the RGD-conjugated albumin NPs remained soluble and dispersed in an aqueous system without any precipitation for up to 4 weeks. ${ }^{5}$ Zhao et al showed that the paclitaxel-loaded BSA NPs exhibited good water solubility by avoiding the Cremophor solvent which induces hypersensitivity reactions, thereby making the drug more biocompatible. ${ }^{6}$ Mathiyalagan et al showed that conjugation with glycol chitosan increased the water solubility of ginsenoside CK. ${ }^{30}$ Thus, the Rh2 loading in BSA nanocarrier contributes to the improved water dispersibility and biocompatibility of the BSA-Rh2 NPs. The enhanced solubility of ginsenosides with biocompatible materials has been previously reported..$^{30}$ 


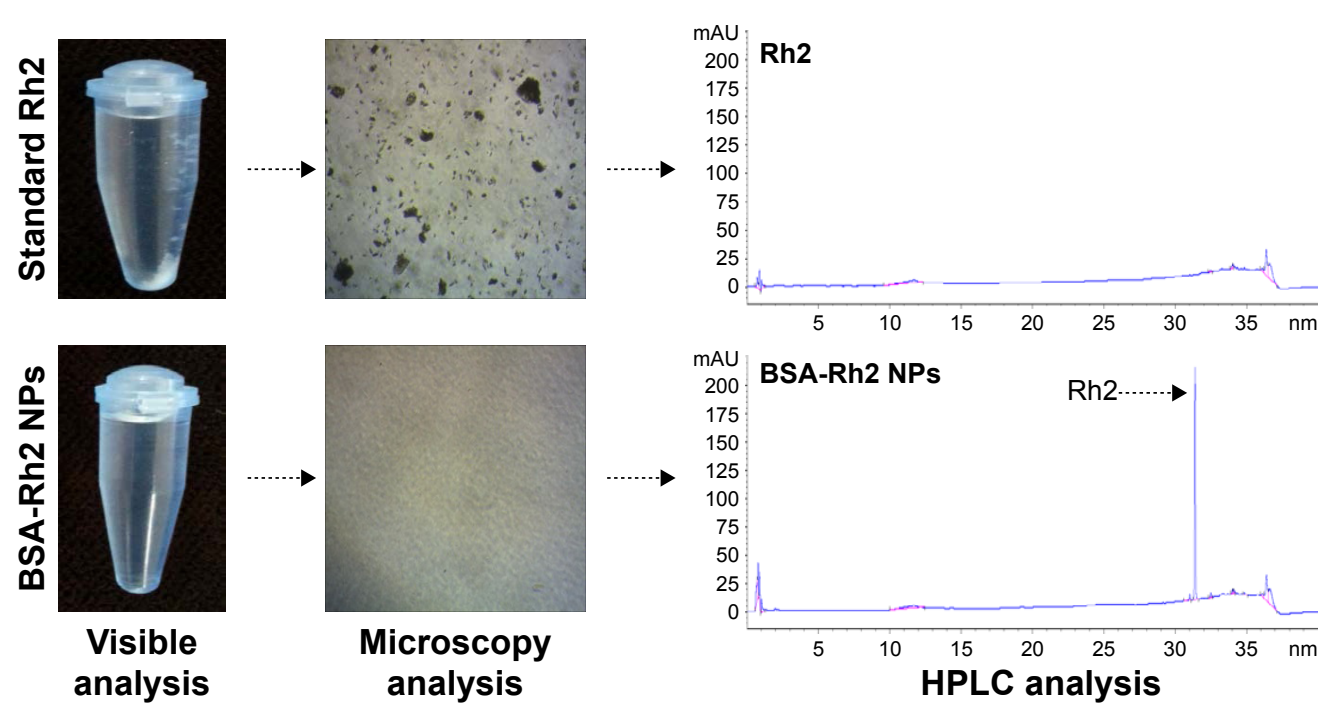

Figure 8 Solubility of free ginsenoside Rh2 and BSA-Rh2 NPs in water, their corresponding microscopic image and HPLC graph of supernatant, respectively. Abbreviations: BSA, bovine serum albumin; HPLC, high-performance liquid chromatography; NPs, nanoparticles.
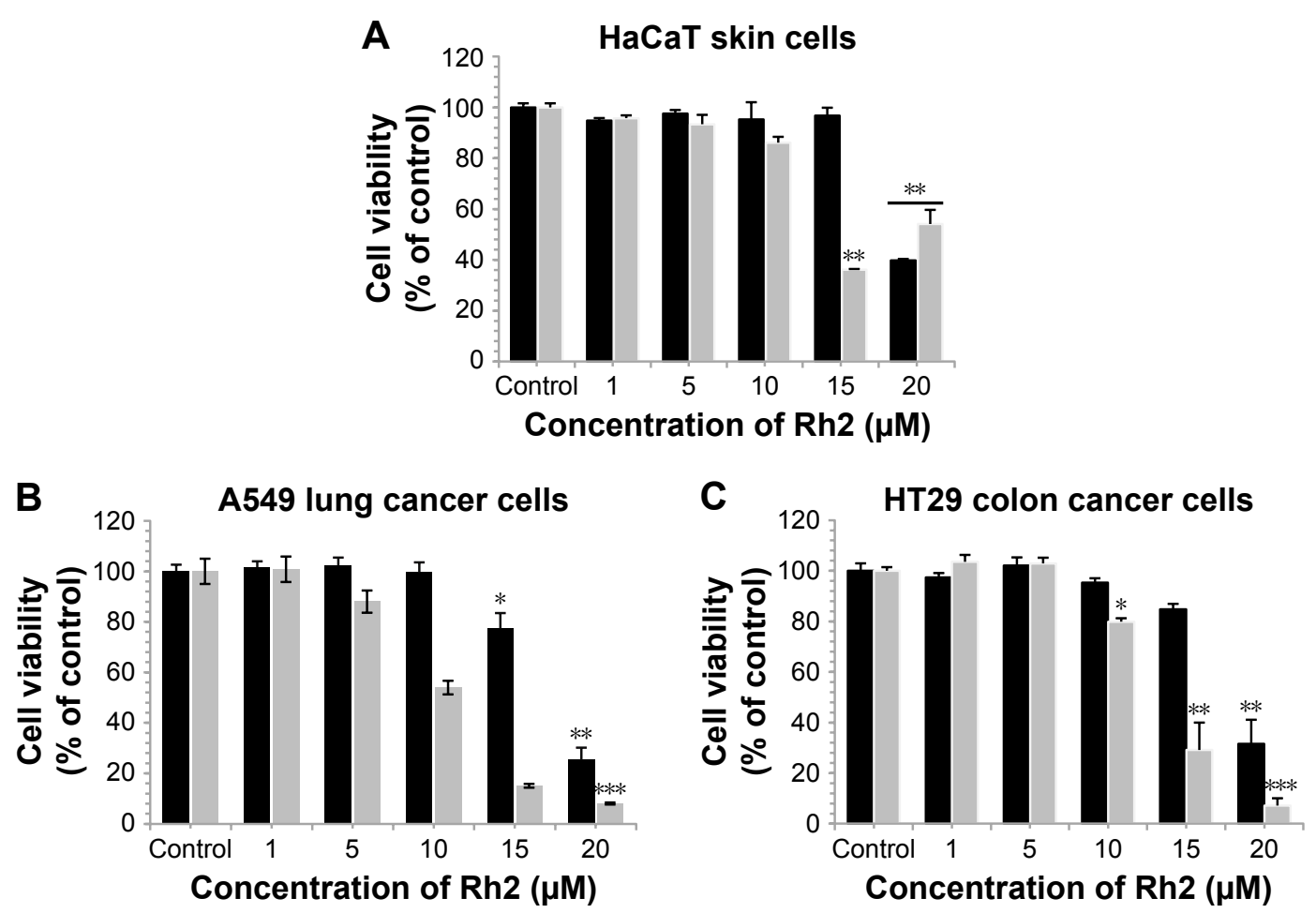

BSA-Rh2 NPs $\square$ Rh2

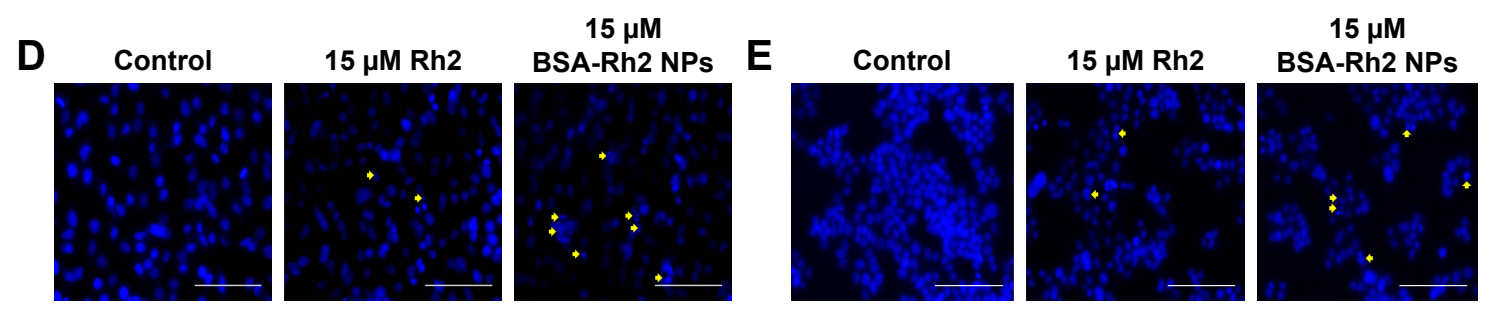

Figure 9 In vitro efficacy of BSA-Rh2 NPs, cell cytotoxicity in HaCaT skin cells (A), A549 lung cancer cell lines (B), HT29 colon cancer cells (C), Hoechst 33258 staining in A549 cells (D), and HT29 colon cancer cells (E).

Notes: Apoptotic cells are indicated with yellow arrows, Scale bar, $10 \mu \mathrm{m}$. Data shown represent the mean values of three experiments \pm SD. $* P<0.05$, $* * P<0.0$, $* * * P<0.00$ I vs control.

Abbreviations: BSA, bovine serum albumin; NPs, nanoparticles. 
In vitro cytotoxicity and anti-inflammatory activity of the BSA-Rh2 NPs

To observe the in vitro cell cytotoxicity and anticancer activity of BSA-Rh2 NPs, we examined the cell cytotoxicity of BSA-Rh2 NPs and standard Rh2 in HaCaT skin cell lines and A549 lung cancer cell lines by MTT assay. For thorough evaluation, we made sure that the BSA-Rh2 NPs were taken such that the concentration of free $\mathrm{Rh} 2$ was comparable to that of the Rh2 entrapped in BSA-Rh2 NPs. As shown in Figure 9A, BSA-Rh2 NPs showed very low cytotoxicity against $\mathrm{HaCaT}$ skin cell lines at $15 \mu \mathrm{M}$ concentration; however, at the same concentration, free Rh2 exhibited significantly higher cell cytotoxicity, which proved that after loading the $\mathrm{Rh} 2$ in a BSA nanocarrier, the cytotoxicity of $\mathrm{Rh} 2$ is reduced. However, in A549 lung cancer cell lines, at the same concentration of $15 \mu \mathrm{M}$, the BSA-Rh2 NPs showed cell cytotoxicity which was much lower as compared with the standard Rh2 (Figure 9B). Importantly, BSA-Rh2 NPs were able to maintain the cell viability in $\mathrm{HaCaT}$ skin cells and cell cytotoxicity in A549 lung cancer cells at $10-15 \mu \mathrm{M}$ concentration. It has been assumed that BSA-Rh2 NPs are watersoluble, and thereby can easily reach tumor cells in a pH-dependent manner, and further release $\mathrm{Rh} 2$ by degradation in tumor cells, thus exerting their anticancer effect (Figure 1). Similarly, in HT29 colon cancer cell lines, BSA-Rh2 NPs showed cytotoxicity at $15 \mu \mathrm{M}$ concentration (Figure 9C), which was significantly lower than $\mathrm{Rh} 2$; however, cell viability in $\mathrm{HaCaT}$ cells was maintained at the same concentration. The results were further confirmed by staining the nuclei of A549 and HT29 cells by Hoechst 33258 dye and quantification of the apoptotic effect of
BSA-Rh2 NPs by HT Titer TACS ${ }^{\text {TM }}$. Our data showed an induction of apoptosis through changes in the nucleus and also the percentage of cells that underwent apoptosis induced by BSA-Rh2 NPs, which was higher at $15 \mu \mathrm{M}$ of BSA-Rh2 NPs as compared to Rh2 (Figure 9D and E). ${ }^{38}$ Reports suggested that $\mathrm{Rh} 2$ may exert an antitumor effect by any of the following possible mechanisms: regulating tumor cells through the signaling pathway system, including the signaling pathway of protein kinase $\mathrm{C}$, insulin-like growth factors, caspase family, and Bcl-2 family; affecting the activity of cell telomerase; blocking anabolism and metabolism of important components of tumor cells; and/or reversing abnormal differentiation and resistance of tumor cells. ${ }^{16}$ Previously, the anticancer efficacy of niclosamide-encapsulated BSA NPs has been explored in A549 lung cancer and MCF-7 breast cancer cell lines, and it was found that the BSA was able to enhance the anticancer efficacy of niclosamide at $5 \mu \mathrm{M}$ concentration as compared with niclosamide drug, by enhancing its stability and water solubility. ${ }^{23}$ In addition, the results showed that the nanoformulation increased the solubility of niclosamide in aqueous medium, so it was easily taken up by the cells and resulted in enhanced anticancer activity in comparison to the free drug. Further, the study showed the similar apoptosis induction mechanism in cancer cells by niclosamideencapsulated BSA NPs as shown by the results of our study (Figure 1). Similar BSA-drug formulations and their applications have been reported, which are in line with our study. ${ }^{39-41}$ However, detailed studies evaluating the cytotoxicity of BSA-Rh2 NPs at cellular level are further required. ${ }^{42-44}$

To further investigate the anti-inflammatory effects of BSA-Rh2 NPs, MTT assay was performed with the Murine

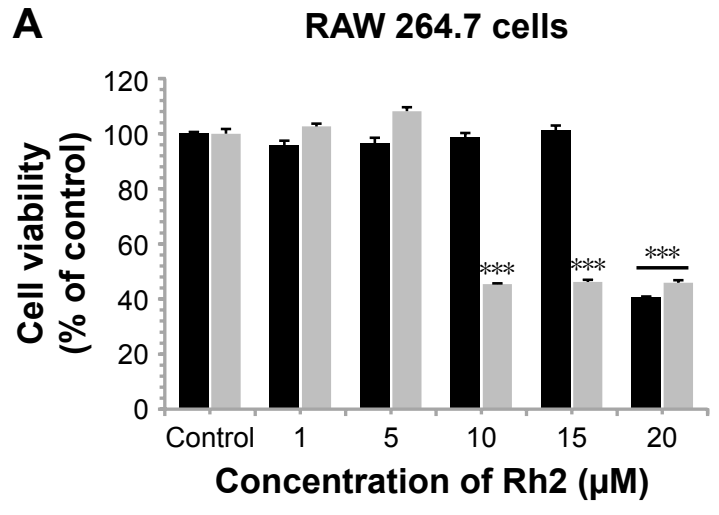

BSA-Rh2 NPs Rh2
B

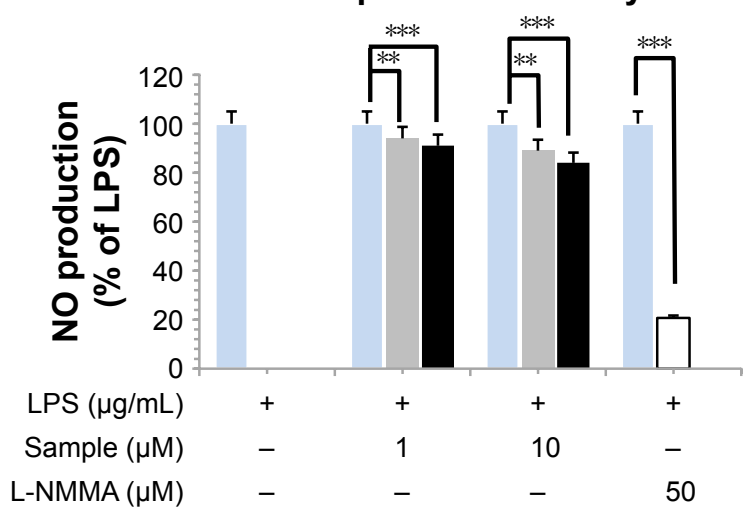

Figure 10 In vitro efficacy of BSA-Rh2 NPs, in RAW 264.7 (murine macrophage) cell lines (A) and inhibition of LPS induced NO production assay (B). Note: Data shown represent the mean values of three experiments $\pm S D$. $* * P<0.0$ I, $* * * P<0.001$ vs control. Abbreviations: BSA, bovine serum albumin; LPS, lipopolysaccharide; NO, nitric oxide; NPs, nanoparticles. 
macrophage cell line (RAW 264.7). The cells were incubated with different concentrations of BSA-Rh2 NPs and standard Rh2. The results exhibited that the BSA-Rh2 NPs showed significantly higher cell viability at 10 and $15 \mu \mathrm{M}$ concentrations unlike Rh2 which showed significant cell cytotoxicity at a concentration range from 10 to $20 \mu \mathrm{M}$ in RAW 264.7 cell line (Figure 10A). Thus, the cell viability assays performed using Raw 264.7 cell line further confirmed the non-cytotoxic nature of BSA-Rh2 NPs. In the nitric acid production assay, BSA-Rh2 NPs showed a higher inhibition of LPS-induced NO production as compared with standard $\mathrm{Rh} 2$ (Figure 10B). ${ }^{33}$ This finding suggests that the BSA-Rh2 NPs have higher and enhanced anti-inflammatory efficacy as compared with standard Rh2. Nevertheless, $\mathrm{Rh} 2$ dissolved in DMSO also showed anticancer and antiinflammatory effects, but use of organic solvent DMSO as a solubilizing agent may lead to severe complications due to cytotoxic effects, and thereby, it is not suitable for clinical applications. In the current study, we avoided the use of DMSO for solubilizing BSA-Rh2 NPs and dissolved NPs in water, thus making them aqueous stable which is advantageous for ginsenosides applicability in therapeutic applications. Collectively, based on in vitro anticancer and anti-inflammatory efficacy assays, we suggest that BSA-Rh2 NPs have more potent anticancer and anti-inflammatory efficacies than standard Rh2. In addition, BSA-Rh2 NPs do not require the use of organic solvents, which increases the water solubility and stability of $\mathrm{Rh} 2$.

Thus, BSA-Rh2 NPs were formed by desolvation method in the backbone of hydrophilic BSA which further enhanced the solubilization of Rh2. In addition, BSA loading with $\mathrm{Rh} 2$ with high stability and excellent biocompatibility was achieved, which allowed eliminating the use of toxic organic compounds such as Cremophor and DMSO for solubilizing Rh2 and for in vitro applications. The results support the excellent water dispersibility and biocompatibility of BSARh2 NPs, which are proved as a potential candidate for anticancer and anti-inflammatory applications as compared with standard $\mathrm{Rh} 2$, with enhanced pharmacological efficacies. ${ }^{44}$ Therefore, the BSA-Rh2 NPs described in this study may be used as a potential candidate to deliver Rh2 for the treatment of human cancer and inflammatory diseases.

\section{Conclusion}

We developed novel Rh2-loaded biodegradable and nontoxic BSA-Rh2 NPs. The analysis of particle size, morphology, and stability indicated that the BSA-Rh2 NPs were quite stable, spherical in shape, and nearly monodispersed in nature. The improved pharmacological efficacies of $\mathrm{Rh} 2$ were demonstrated using in vitro cytotoxicity assays in various cell lines. The results supported the biocompatible nature of the BSA nanocarrier and showed that BSA sufficiently enhanced the anticancer ability of Rh2 in A549 lung cancer and HT29 colon cancer cells compared to free $\mathrm{Rh} 2$ in aqueous medium. Additionally, BSA-Rh2 NPs were found to possess good anti-inflammatory effect compared to free Rh2. Overall, these results suggest that BSA-Rh2 NPs may be potentially useful as vehicles for intracellular release of Rh2. The current study utilized BSA as a proof-of-concept investigation; in future, HSA could be used in the place of BSA, to avoid any feasible immunologic response in in vivo trials. Thus, our study proposes that the solubility and chemotherapeutic potential of $\mathrm{Rh} 2$ could be better employed by loading it in a BSA nanocarrier for future therapeutic applications.

\section{Acknowledgment}

This study was supported by a grant from the National Research Foundation of Korea (NRF-2012M3A9B8021791) and the Next-Generation BioGreen 21 Program (SSAC, grant \#: PJ0120342016), Rural Development Administration, Republic of Korea.

\section{Disclosure}

The authors report no conflicts of interest in this work.

\section{References}

1. Bae KH, Chung HJ, Park TG. Nanomaterials for cancer therapy and imaging. Mol Cells. 2011;31(4):295-302.

2. Singh R, Lillard JW Jr. Nanoparticle-based targeted drug delivery. Exp Mol Pathol. 2009;86(3):215-223.

3. De Jong WH, Borm PJ. Drug delivery and nanoparticles: applications and hazards. Int J Nanomedicine. 2008;3(2):133-149.

4. Lohcharoenkal W, Wang L, Chen YC, Rojanasakul Y. Protein nanoparticles as drug delivery carriers for cancer therapy. Biomed Res Int. 2014;2014:180549.

5. Ji S, Xu J, Zhang B, et al. RGD-conjugated albumin nanoparticles as a novel delivery vehicle in pancreatic cancer therapy. Cancer Biol Ther 2012;13(4):206-215.

6. Zhao D, Zhao X, Zu Y, et al. Preparation, characterization, and in vitro targeted delivery of folate-decorated paclitaxel-loaded bovine serum albumin nanoparticles. Int J Nanomedicine. 2010;5:669-677.

7. Kratz F. Albumin as a drug carrier: design of prodrugs, drug conjugates and nanoparticles. J Control Release. 2008;132(3):171-183.

8. Elsadek B, Kratz F. Impact of albumin on drug delivery-new applications on the horizon. J Control Release. 2012;157(1):4-28.

9. Miele E, Spinelli GP, Miele E, Tomao F, Tomao S. Albumin-bound formulation of paclitaxel (Abraxane ABI-007) in the treatment of breast cancer. Int J Nanomedicine. 2009;4:99-105.

10. Chen $\mathrm{C}, \mathrm{Hu} \mathrm{H}$, Qiao $\mathrm{M}$, et al. Tumor-targeting and $\mathrm{pH}$-sensitive lipoprotein-mimic nanocarrier for targeted intracellular delivery of paclitaxel. Int J Pharm. 2015;480(1-2):116-127.

11. Jithan A, Madhavi K, Madhavi M, Prabhakar K. Preparation and characterization of albumin nanoparticles encapsulating curcumin intended for the treatment of breast cancer. Int J Pharm Investig. 2011; 1(2):119-125. 
12. Choi JH, Hwang HJ, Shin SW, Choi JW, Um SH, Oh BK. A novel albumin nanocomplex containing both small interfering RNA and gold nanorods for synergetic anticancer therapy. Nanoscale. 2015;7(20): 9229-9237.

13. Bi WY, Fu BD, Shen HQ, et al. Sulfated derivative of 20(S)-ginsenoside $\mathrm{Rh} 2$ inhibits inflammatory cytokines through MAPKs and NF-kappa B pathways in LPS-induced RAW264.7 macrophages. Inflammation. 2012;35(5):1659-1668.

14. Kang S, Min H. Ginseng, the 'Immunity Boost': the effects of Panax ginseng on immune system. J Ginseng Res. 2012;36(4):354-368.

15. Huang YC, Lin CY, Huang SF, Lin HC, Chang WL, Chang TC. Effect and mechanism of ginsenosides $\mathrm{CK}$ and $\mathrm{Rg} 1$ on stimulation of glucose uptake in 3T3-L1 adipocytes. J Agric Food Chem. 2010;58(10): 6039-6047.

16. Tang XP, Tang GD, Fang CY, Liang ZH, Zhang LY. Effects of ginsenoside $\mathrm{Rh} 2$ on growth and migration of pancreatic cancer cells. World J Gastroenterol. 2013;19(10):1582-1592.

17. Kim HS, Lee EH, Ko SR, Choi KJ, Park JH, Im DS. Effects of ginsenosides Rg3 and Rh2 on the proliferation of prostate cancer cells. Arch Pharm Res. 2004;27(4):429-435.

18. Li LC, Piao HM, Zheng MY, Lin ZH, Choi YH, Yan GH. Ginsenoside $\mathrm{Rh} 2$ attenuates allergic airway inflammation by modulating nuclear factor- $\mathrm{KB}$ activation in a murine model of asthma. Mol Med Rep. 2015; 12(5):6946-6954.

19. Wang CZ, Li XL, Wang QF, et al. The mitochondrial pathway is involved in American ginseng-induced apoptosis of SW-480 colon cancer cells. Oncol Rep. 2009;21(3):577-584.

20. Wu XZ, Xie GR. Induced differentiation of hepatocellular carcinoma by natural products. Afr J Tradit Complement Altern Med. 2008;5(4): 325-331.

21. Qu X, Qu S, Yu X, et al. pseudo-G-Rh2 induces mitochondrial-mediated apoptosis in SGC-7901 human gastric cancer cells. Oncol Rep. 2011; 26(6):1441-1446.

22. Choi S, Oh JY, Kim SJ. Ginsenoside Rh2 induces Bcl-2 family proteinsmediated apoptosis in vitro and in xenografts in vivo models. $J$ Cell Biochem. 2011;112(1):330-340.

23. Bhusan B, Dubey P, Kumar SU, Sachdev A, Matai I, Gopinath P. Bionanotherapeutics: niclosamide encapsulated albumin nanoparticles as a novel drug delivery system for cancer therapy. RSC Adv. 2015; 5(16):12078-12086.

24. Singh P, Kim YJ, Wang C, Mathiyalagan R, Yang DC. Microbial synthesis of flower-shaped gold nanoparticles. Artif Cells Nanomed Biotechnol. 2016;44(6):1469-1474.

25. Singh P, Kim YJ, Singh H, Mathiyalagan R, Wang C, Yang DC. Biosynthesis of anisotropic silver nanoparticles by Bhargavaea indica and their synergistic effect with antibiotics against pathogenic microorganisms. J Nanomater. 2015;2015:10.

26. Singh P, Kim YJ, Yang DC. A strategic approach for rapid synthesis of gold and silver nanoparticles by Panax ginseng leaves. Artif Cells Nanomed Biotechnol. 2016;44(8):1949-1957.

27. Singh P, Kim YJ, Wang C, Mathiyalagan R, El-Agamy Farh M, Yang DC. Biogenic silver and gold nanoparticles synthesized using red ginseng root extract, and their applications. Artif Cells Nanomed Biotechnol. 2016;44(3):811-816.

28. Singh P, Kim YJ, Singh H, et al. Biosynthesis, characterization, and antimicrobial applications of silver nanoparticles. Int J Nanomedicine. $2015 ; 10: 2567-2577$.

International Journal of Nanomedicine

\section{Publish your work in this journal}

The International Journal of Nanomedicine is an international, peerreviewed journal focusing on the application of nanotechnology in diagnostics, therapeutics, and drug delivery systems throughout the biomedical field. This journal is indexed on PubMed Central, MedLine, CAS, SciSearch ${ }^{\circledR}$, Current Contents ${ }^{\circledR} /$ Clinical Medicine,
29. Singh P, Kim YJ, Wang C, Mathiyalagan R, Yang DC. The development of a green approach for the biosynthesis of silver and gold nanoparticles using Panax ginseng root extract, and their biological applications. Artif Cells Nanomed Biotechnol. 2016;44(4):1150-1157.

30. Mathiyalagan R, Subramaniyam S, Kim YJ, Kim YC, Yang DC. Ginsenoside compound K-bearing glycol chitosan conjugates: synthesis, physicochemical characterization, and in vitro biological studies. Carbohydr Polym. 2014;112:359-366.

31. Castro-Aceituno V, Ahn S, Simu SY, et al. Anticancer activity of silver nanoparticles from Panax ginseng fresh leaves in human cancer cells. Biomed Pharmacother. 2016;84:158-165.

32. Ahn S, Singh P, Castro-Aceituno V, et al. Gold nanoparticles synthesized using Panax ginseng leaves suppress inflammatory - mediators production via blockade of NF- $\mathrm{KB}$ activation in macrophages. Artif Cells Nanomed Biotechnol. 2017;45(2):270-276.

33. Ahn S, Siddiqi MH, Aceituno VC, et al. Ginsenoside Rg5:Rk1 attenuates TNF- $\alpha /$ IFN- $\gamma$-induced production of thymus- and activation-regulated chemokine (TARC/CCL17) and LPS-induced NO production via downregulation of NF- $\mathrm{KB} / \mathrm{p} 38$ MAPK/STAT1 signaling in human keratinocytes and macrophages. In Vitro Cell Dev Biol Anim. 2016; 52(3):287-295.

34. Neumann E, Frei E, Funk D, et al. Native albumin for targeted drug delivery. Expert Opin Drug Deliv. 2010;7(8):915-925.

35. Langer K, Anhorn MG, Steinhauser I, et al. Human serum albumin (HSA) nanoparticles: reproducibility of preparation process and kinetics of enzymatic degradation. Int J Pharm. 2008;347(1-2):109-117.

36. Gebregeorgis A, Bhan C, Wilson O, Raghavan D. Characterization of Silver/Bovine Serum Albumin (Ag/BSA) nanoparticles structure: morphological, compositional, and interaction studies. J Colloid Interface Sci. 2013;389(1):31-41.

37. Singh P, Singh H, Kim YJ, Mathiyalagan R, Wang C, Yang DC. Extracellular synthesis of silver and gold nanoparticles by Sporosarcina koreensis DC4 and their biological applications. Enzyme Microb Technol. 2016;86:75-83.

38. Collins TJ. ImageJ for microscopy. Biotechniques. 2007;43(1 Suppl): S25-S30.

39. Li FQ, Su H, Wang J, et al. Preparation and characterization of sodium ferulate entrapped bovine serum albumin nanoparticles for liver targeting. Int J Pharm. 2008;349(1-2):274-282.

40. Murawala P, Phadnis SM, Bhonde RR, Prasad BL. In situ synthesis of water dispersible bovine serum albumin capped gold and silver nanoparticles and their cytocompatibility studies. Colloids Surf B Biointerfaces. 2009;73(2):224-228.

41. Nayar S, Sinha A, Das S, Rao PR. In situ synthesis of nanosized cadmium sulfide using bovine serum albumin. J Mater Sci Lett. 2001; 20(23):2099-2100

42. Kumar RS, Jha A. Synthesis of silver nanoparticles using bovine serum albumin, characterization and their bioevaluation. Indian J Appl Res. 2011;3(10): 1-3

43. Singh AV, Patil R, Kasture MB, Gade WN, Prasad BL. Synthesis of Ag-Pt alloy nanoparticles in aqueous bovine serum albumin foam and their cytocompatibility against human gingival fibroblasts. Colloids Surf B Biointerfaces. 2009;69(2):239-245.

44. Mathiyalagan R, Kim YJ, Wang C, et al. Protopanaxadiol aglycone ginsenoside-polyethylene glycol conjugates: synthesis, physicochemical characterizations, and in vitro studies. ArtifCells Nanomed Biotechnol. 2016;44(8):1803-1809.

Journal Citation Reports/Science Edition, EMBase, Scopus and the Elsevier Bibliographic databases. The manuscript management system is completely online and includes a very quick and fair peer-review system, which is all easy to use. Visit http://www.dovepress.com/ testimonials.php to read real quotes from published authors. 